\title{
Isolation and Purification Chemical Compound from Melissa officinalis
}

\author{
Jamal A. Nasser \\ \# School of Chemical Sciences, Arhab collage, Sana'a University, Yemen \\ E-mail: jamal.nasser2009@gmail.com
}

\begin{abstract}
A chemical study was done on the leaves of Melissa officinalis. The separations of the chemical components were carried out by different chromatographic techniques and their structures were elucidated by spectroscopic method including nuclear magnetic resonance as well as gas chromatography-mass spectrometry. Three compounds were isolated and identified as friedoolean-7-one , stigmasterol and betulinic acid.
\end{abstract}

Keywords - Leaves of Melissa officinalis; friedo-olean-7-one; Stigmasterol; betulinic acid; NMR analysis

\section{INTRODUCTION}

Melissa officinalis known as balm [2] or balm mint, is a perennial herb in the mint family Lamiaceae, native to southcentral Europe and the Mediterranean region. It grows to 70$150 \mathrm{~cm}$ tall. The leaves have a gentle lemon scent, related to mint. During summer, small white flowers full of nectar appear. It is not to be confused with bee balm (which is genus Monarda). The white flowers attract bees, hence the genus name Melissa (Greek for 'honey bee'). It's flavour comes from citronellal (24\%), geranial (16\%), linalyl acetate $(12 \%)$ and caryophyllene (12\%)(1). Melissa often used as a flavouring in ice cream and herbal teas, both hot and iced, often in combination with other herbs such as spearmint. It is also frequently paired with fruit dishes or candies. It can be used in fish dishes and is the key ingredient in lemon balm pesto. It might be a better, healthier preservative than butylated hydroxy anisole in sausages (2), In the traditional Austrian medicine, M. officinalis leaves have been prescribed for internal (as tea) or external (essential oil) application for the treatment of disorders of the gastrointestinal tract, nervous system, liver, and bile.[3].

Melissa essential oil is very popular in aromatherapy. The essential oil is commonly codistilled with lemon oil, citronella oil, or other oils.

\section{EXPERIMENTAL}

TLC and preparative TLC were performed using precoated alumi nium and glass plates with silica gel $60 \mathrm{~F}_{254}$, whereas column chromatography was carried out on silica gels 230-400 mesh. Spots and bands for compounds on TLC were detected using UV light.

UV spectra were recorded on a UV1650PC spectrophoto meter. ${ }^{1} \mathrm{H}$ NMR $(400 \mathrm{MHz})$ and ${ }^{13} \mathrm{C} \quad \mathrm{NMR} \quad(100 \mathrm{MHz})$ spectra were recorded on JEOL JNM-ECP400 and chemical shifts in ppm were referenced to internal acetone- $\mathrm{d}_{6}$ and $\mathrm{CDCl}_{3}$, respectively.

\section{A. Plant Material}

The leave of Melissa officinalis were collected from the field from Sana'a . A voucher specimen had been deposited at the Herbarium of University.

\section{B. Extraction and isolation}

The air-dried powder leaves (700 g) of Melissa officinalis was extracted (Soxhlet) with ethanol (2X, 8 hours each) and the combined extracts evaporated to give a green gummy residue $(3 \mathrm{~g})$. This extract was subjected to silica gel flash column chromatography (FCC) with chloroform containing increasing percentages of methanol as eluent and each collected fraction was $20 \mathrm{ml}$. Fractions 1- 4 were combined and rechromatographed by radial chromatography to yielded M1 (3.6 mg) identified as betulinic acid (1), Rf 0.50 (hexane-EtOAc), M2 (3.0 mg) identified as Stigmasterol (2) \& M3 (4.2) identified as friedo-olean-7-one(3), were 
identified by comparison with data from previous NMR and mass spectra (Horinouchi, et. al. 1988, A. A. Leslie Gunatilaka et al. 1982.

\section{RESULTS AND DISCUSSION}

The concentrated methanol extract of the leaves of Melissa officinalis was repeatedly chromatographed over silica gel flash column chromatography, and compound 1-3 were eluted in the order of tier increasing polarity. The ${ }^{1} \mathrm{H}$ and ${ }^{13} \mathrm{C}$ NMR spectral data for these compounds revealed that 1 and 3 belong to the triterpene group Compound 2 was identified as Stigmasterol from its physical constants, spectral data and by a direct comparison with an authentic sample.

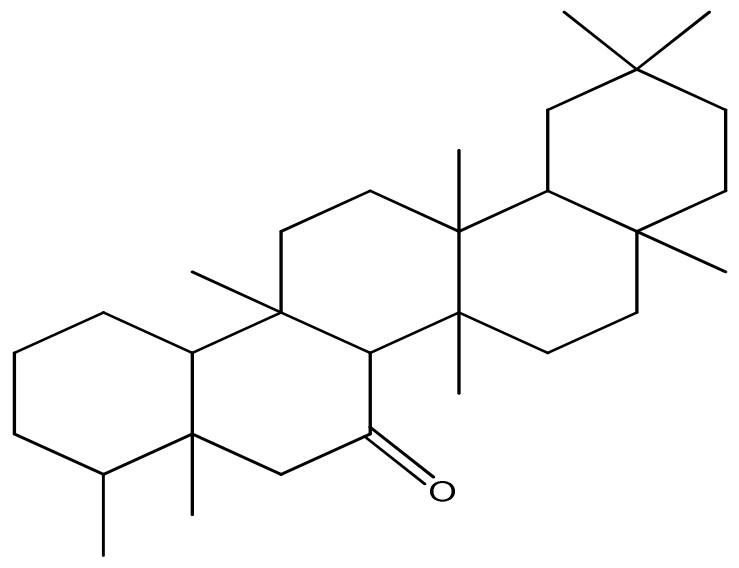

Fig.1 friedo-olean-7-one

are composed of five six membered rings A-E.was isolated as white powder. The mass spectral data of the compound gave a molecular formula $\mathrm{C}_{30} \mathrm{H}_{50} \mathrm{O}, \mathrm{m} / \mathrm{z} 426 \mathrm{M}^{+}$. ${ }^{1} \mathrm{H}$ NMR (400 MHZ, $\mathrm{CDCL}_{3}$ ) spectra showed the presence of seven methyl's appeared at $\delta 0.68,0.79,0.82,0.86,0.92$ and 1.02 . ${ }^{13} \mathrm{C}$ NMR showed thirty carbons signal including eight methyles, eleven methylenes, four methins and seven quaternary carbons. The carbonyl carbons appeared at $\delta$ 212.3.

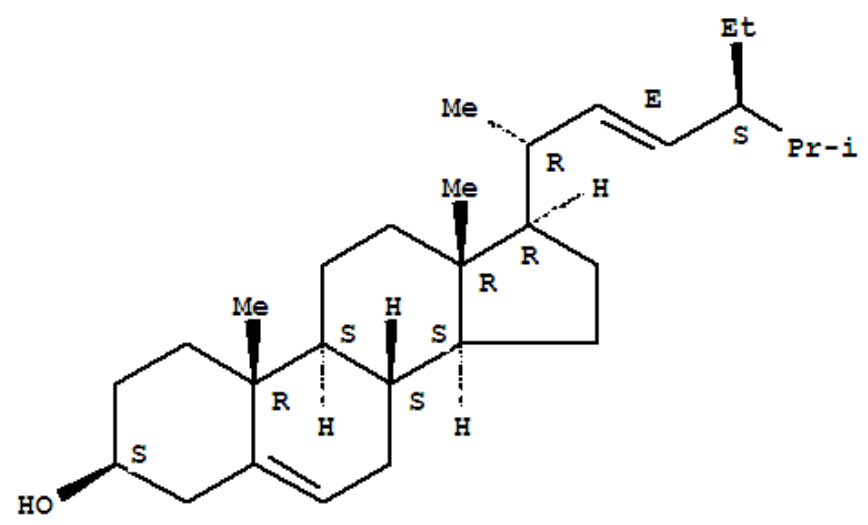

Fig.2 Stigmasterol was isolated as white powder. The mass spectral data of the compound gave a molecular formula $\mathrm{C}_{29} \mathrm{H}_{42} \mathrm{O}$, m/z $412 \mathrm{M}^{+}$. ${ }^{1} \mathrm{H}$ NMR (400 MHZ, $\mathrm{CDCL}_{3}$ ) spectra showed the presence of six methyl's appeared at $\delta 0.68,0.79,0.82,0.86,0.92$ and 1.02. The proton of $\mathrm{H}-3$ appeared as a multiplet at $\delta 3.53$. It also showed olefinic protons at $\delta 5.36,5.15$ and $5.01 .{ }^{13} \mathrm{C}$ NMR and APT showed twenty nine carbon signal including six methyles, nine methylenes, eleven methins and three quaternary carbons. The alkenes carbons appeared at $\delta 140.0$, 138.5, 129.5 and 122.6. Stigmasterol isolated from Mellisa for first time, it was reported in many plants as schefflera arboricola , Chlorella ellipsoidea, Teucrium abutiloides and T. Betonicum ${ }^{(4,5)}$

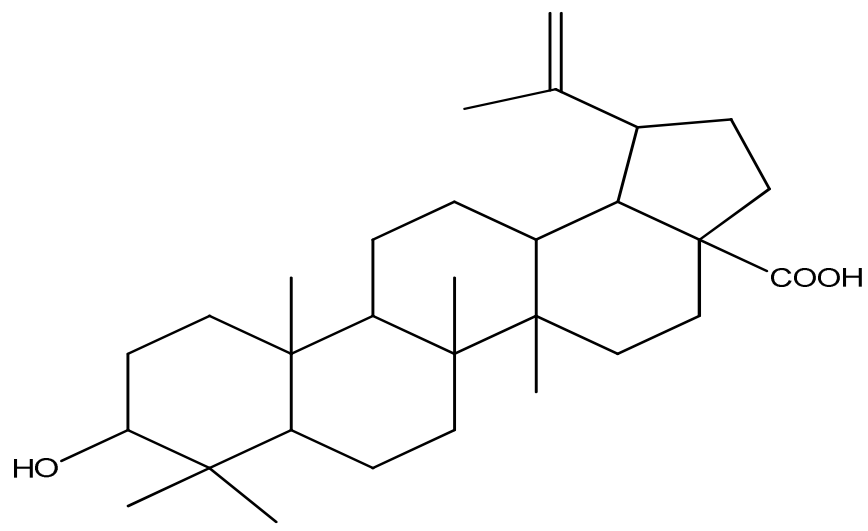

Fig.3 betulinic acid

was isolated as white powder. The ${ }^{1} \mathrm{H}$ NMR (400 MHZ, $\mathrm{CDCL}_{3}$ ) spectra showed the presence of six methyl's appeared at $0.83,1.02,1.07,1.08,1.23,1.80 \mathrm{~Hz}$. The proton of $\mathrm{H}-3$ appeared as a multiplet at $\delta 3.55$. It also showed methyl protons at $\delta 2.26$. It also showed olefinic protons at $\delta$ $4.78 \& 4.95 .{ }^{13} \mathrm{C}$ NMR showed thirty carbon signal including six methyles, eleven methylenes, six methins and seven quaternary carbons. The alkenes carbons appeared at $\delta 109.78 \& 151.90$. the carboxylic carbon appeared at $\delta$ 178.85. betulinic acid isolated from Mellisa for first time $^{(6)}$.

\section{CONCLUSIONS}

This work was aimed to isolate and identify of ; friedoolean-7-one (1), stigmasterol (2) and betulinic acid (3) from the leaves of Melissa officinalis. This was the first ever to be done and reported from this plant. It was carried out by means of various physical (solvent extraction, radial chromatography) and spectral techniques.

\section{ACKNOWLEDGMENT}

Thanks are due to the Center for Research and Innovation Management, Universiti Kebangsaan Malaysia for recording necessary data using the NMR, UV \& IR instruments. also grateful to the Ministry of Higher Education Yemen and Sana'a University of Yemen for financial assistance under the Fundamental Research Grand 


\section{REFERENCES}

[1] Chisholm, Hugh, ed. (1911). "Balm". Encyclopædia Britannica 3 (11th ed.). Cambridge University Press.

[2] de Ciriano M.G.-I., Rehecho S., Calvo M.I., Cavero R.Y., Navarro I., Astiasarán I., Ansorena D.,"Effect of lyophilized water extracts of Melissa officinalis on the stability of algae and linseed oil-in-water emulsion to be used as a functional ingredient in meat products", Meat Science 2010 85:2 (373-377).

[3] Vogl, S; Picker, P; Mihaly-Bison, J; Fakhrudin, N; Atanasov, AG; Heiss, EH; Wawrosch, C; Reznicek, $G$ et al. (2013). "Ethnopharmacological in vitro studies on Austria's folk medicine-
An unexplored lore in vitro anti-inflammatory activities of 71 Austrian traditional herbal drugs". Journal of Ethnopharmacology 149 (3): 750-71.

[4] Alam, M. Sarwar, Chopra, Neeraj, Ali, Mohammed and Niwa, Masatake, 1996. Oleanen and stigmasterol derivatives from Ambroma augusta", Phytochemistry 41, pp. 1197-1200.

[5] Singh, Harkishan, Kapoor, Vijay K., Piozzi, Franco, Passannanti, Salvatore and Paternostro, Mariapia, 1978. Isomotiol, a new triterpene from strychnos potatorum", Phytochemistry 17, 154-155

[6] Akira I. \& Hideji I.,. Triterpenoids of paeonia japonzca callus tissue. Tokyo College of Pharmacy, 1432-1, 1988. 